\title{
ESA21
}

\section{Drinking Water Treatment}

Table of Contents:

History of Water Treatment

Drinking Water Treatment Process

Activity: Simulated Drinking Water Treatment Plant

Activity: Constructing the Filtering Apparatus

\section{History of Water Treatment}

Water has always played a prominent role in human civilization. When people first began settling in one place and growing crops for sustenance, it was invariably near water sources like rivers, lakes, or groundwater springs. Water was needed for drinking, preparing food, bathing, cleaning, irrigating crops, and a variety of other tasks, so it was important to have ready access to this resource. The water sources used for supplying water were not always clean however, and treating drinking water to improve smell, taste, clarity, or to remove disease-causing pathogens has occurred in one form or another throughout recorded history. Begin by reviewing the history of drinking water treatment with the

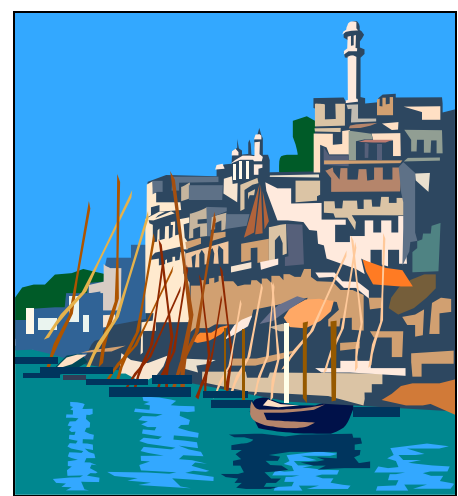
document below from the U.S. EPA.

The History of Drinking Water Treatment (PDF) (376 KB)

Water treatment over time, summary of modern treatment methods

United States Environmental Protection Agency

http://www.epa.gov/safewater/consumer/hist.pdf

\section{Drinking Water Treatment Process}

Now that you are familiar with drinking water treatment, let's examine modern methods in greater detail. In general, the treatment of drinking water by municipal water systems involves a few key steps:

Aeration: $\quad$ The water is mixed to liberate dissolved gases and to suspended particles in the water column. 
Flocculation: The materials and particles present in drinking water (clay, organic material, metals, microorganisms) are often quite small and so will not settle out from the water column without assistance. To help the settling process along, "coagulating" compounds are added to the water, and suspended particles "stick" to these compounds and create large and heavy clumps of material.

Sedimentation: The water is left undisturbed to allow the heavy clumps of particles and coagulants to settle out.

Filtration: $\quad$ The water is run through a series of filters which trap and remove particles still remaining in the water column. Typically, beds of sand or charcoal are used to accomplish this task.

Disinfection: The water, now largely free of particles and microorganisms, is treated to destroy any remaining disease-causing pathogens. This is commonly done with chlorination (the same process used to eliminate pathogens in swimming pools), ozone, or ultraviolet radiation. The water is now safe to drink and is sent to pumping stations for distribution to homes and businesses.

Examine in detail the process of drinking water treatment and its relationship to human health with the resources below. Once your review of this material is complete, proceed to the Activity.

\author{
Drinking Water Treatment (PDF) (481 KB) \\ A detailed examination of municipal drinking water treatment methods \\ United States Environmental Protection Agency \\ http://www.epa.gov/safewater/faq/treatment.pdf
}

Drinking Water and Health: What You Need to Know! (PDF) (996 KB)

Overview of potential contaminants in drinking water and related health effects

United States Environmental Protection Agency

http://www.epa.gov/safewater/dwh/dw-health.pdf

\title{
Activity: Simulated Drinking Water Treatment Plant
}

In this activity we'll be treating "contaminated" water to observe firsthand the steps involved in purifying water for human consumption. The activity will use everyday items to carry out the steps in drinking water treatment and you will record changes in the water's properties as the process progresses. The basic version of this exercise has you record the appearance and odor of untreated water as it moves through the various steps. In some situations, depending on available equipment and personnel, you may also be able to measure turbidity. Turbidity describes the clarity or "muddiness" of a water sample and is measured by examining the transmission of light through a water sample. Turbidity is a particularly useful measure of water quality for this exercise, as it enables one to quantitatively track changes in the water sample as it moves through the treatment process. Check with your lab instructor to see if turbidity measurements will be taken when you perform the exercise. Directions for measuring turbidity, if applicable, will be provided by your lab instructor. 
This exercise is a modified version of the Water Filtration exercise from EPA's Environmental Education materials, and can be found with other exercises at http://www.epa.gov/safewater/kids/grades 4-8 water filtration.html .

\section{Activity: Constructing the Filtering Apparatus}

The activity requires the construction of an apparatus for filtering the water sample. Directions for constructing the apparatus and a complete list of materials are provided below.

\begin{tabular}{|c|l|}
\hline (1.) & Obtain a plastic two-liter soda bottle with the bottom removed. \\
\hline (2.) & Secure a coffee filter to the neck of the bottle with a rubber band. \\
\hline (3.) & Turn the bottle upside down and secure it in place as described by your instructor. \\
\hline (4.) & $\begin{array}{l}\text { Gently add } 400 \mathrm{ml} \text { of pebbles to the bottle. Make sure the pebbles do not puncture } \\
\text { the coffee filter. }\end{array}$ \\
\hline (5.) & $\begin{array}{l}\text { Gently add } 800 \mathrm{ml} \text { of coarse sand on top of the pebbles. Avoid shaking the bottle } \\
\text { whenever possible. }\end{array}$ \\
\hline (6.) & Gently add $800 \mathrm{ml}$ of fine sand on top of the coarse sand. Again, avoid shaking. \\
\hline (7.) & $\begin{array}{l}\text { Place a clean } 500 \mathrm{ml} \text { beaker beneath the inverted neck of the bottle to collect the } \\
\text { water from the apparatus. }\end{array}$ \\
\hline (8.) & $\begin{array}{l}\text { Clean the sand and pebbles by slowly pouring } 5 \text { liters of clean tap water (in } 400 \mathrm{ml} \\
\text { increments to avoid overflowing the beaker) through the apparatus. Take steps to } \\
\text { minimize the disturbance to the uppermost sand layer as you pour. }\end{array}$ \\
\hline (9.) & $\begin{array}{l}\text { Once the flushing of the filtering apparatus is complete, thoroughly rinse the collection } \\
\text { beaker with tap water and return it to its place beneath the bottle. Your apparatus is } \\
\text { now complete and ready for use. }\end{array}$ \\
\hline
\end{tabular}

\section{Filtering Apparatus Diagram:}

(http://www.epa.gov/safewater/kids/filter.pdf)

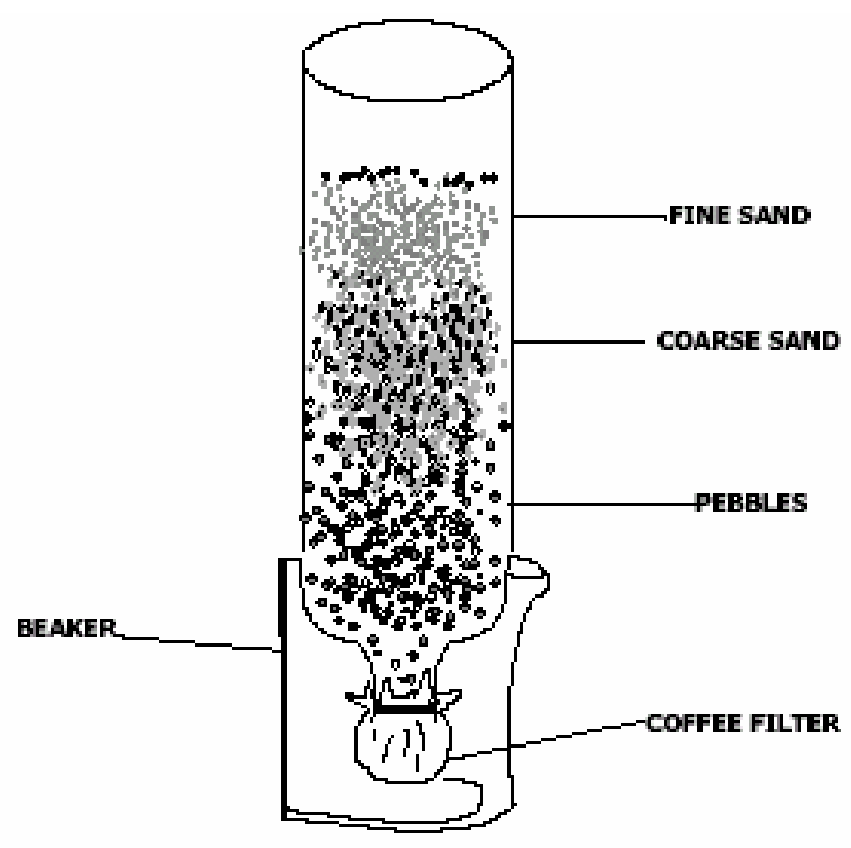




\section{Materials:}

To view the original exercise's materials and procedures, visit the EPA's Water Education page at http://www.epa.gov/safewater/kids/grades 4-8 water filtration.html .

For each station, the following materials are required:

$1.5 \mathrm{~L}$ of "contaminated water" (batch prepare as 2.5 cups of dirt to $5 \mathrm{~L}$ of tap water)

1 two-liter plastic soda bottle + cap, with bottom removed

2 two-liter plastic soda bottles with top (cap through base of neck) removed

20 grams alum (potassium aluminum sulfate), approximately 2 tablespoons

$800 \mathrm{ml}$ fine sand

$800 \mathrm{ml}$ coarse sand

$400 \mathrm{ml}$ small pebbles

$500 \mathrm{ml}$ (or larger) beaker

1 coffee filter

1 rubber band

1 tablespoon for alum

1 stopwatch (clock in room may substitute) 


\section{ESA 21: Environmental Science Activities}

Name:

Instructor:

Activity: Simulated Drinking Water Treatment Plant

[WARNING]: The water used in the experiment is not suitable for drinking at any stage in treatment. Hence, do not consume the water under any circumstances.

Begin by familiarizing yourself with the lab procedures. It is important that you know the steps well as mistakes may cause you to begin anew in the process. If you are able to record turbidity measurements, obtain these measurements and

\section{Contaminated Water}

Cap and shake the container of contaminated water, and pour $1.5 \mathrm{~L}$ into one of the empty twoliter bottles. Describe the appearance and odor (and turbidity, if appropriate) of the water.

\begin{tabular}{|c|l|}
\hline Appearance: & \\
\hline Odor: & \\
\hline Turbidity: & \\
\hline
\end{tabular}

\section{Step 1: Aeration}

Cap the two liter bottle and aerate the water by shaking it vigorously for 30 seconds. Pour the water into one of the cut-off two liter bottles, and then pour the water back and forth between the cut-off two-liter bottles five times. Once you are done, describe the appearance and odor (and turbidity, if appropriate) of the water.

\begin{tabular}{|c|l|}
\hline Appearance: & \\
\hline Odor: & \\
\hline Turbidity: & \\
\hline
\end{tabular}




\section{Step 2: Coagulation}

The water should be in one of the cut-off two-liter bottles. Add 20 grams of alum crystals to the container and stir gently for 5 minutes. The alum will act as a coagulant and bind with the particles suspended in the water. Describe the what happens to the appearance of the water during the 5 minutes.

Appearance:

Step 3: Sedimentation

Leave the container undisturbed for 20 minutes, and record observations of the water's appearance (and take turbidity readings, if appropriate) at 5 minute intervals.

\begin{tabular}{|c|c|c|}
\hline Time (min.) & Appearance & Turbidity \\
\hline 5 & & \\
\hline 10 & & \\
\hline 15 & & \\
\hline 20 & & \\
\hline
\end{tabular}

\section{Step 4: Filtration}

Construct the filter apparatus as directed. Carefully (and we mean carefully) and slowly (and we mean slowly) pour off the top two-thirds of the water in the container into a clean beaker. It is important that you do not disturb the sediment when pouring, so take a great deal of care during this step. Allow the water to settle, and then pour $400 \mathrm{ml}$ of water from the beaker into the filter apparatus. The water will percolate through the sand and pebbles and collect in the beaker beneath the apparatus. Describe the appearance and odor (and turbidity, if appropriate) of the water after it has been filtered. Pour the remaining water and sediment in the two-liter bottle back into the container of contaminated water.

\begin{tabular}{|c|l|}
\hline Appearance: & \\
\hline Odor: & \\
\hline Turbidity: & \\
\hline
\end{tabular}




\section{Step 5: Disinfection}

The final step in the process, the elimination of any remaining microorganisms, will not be done in this exercise. This is normally an important step in the process, but as the water is not to be consumed and disinfection methods can be dangerous outside of controlled conditions, this step will not done in this exercise.

\section{Analyzing Results:}

Create a graph that displays the observed changes in the quality of the water throughout the treatment process. If you measured turbidity, graph the turbidity measurements versus treatment step. If you did not measure turbidity, assign a scale to your appearance and/or odor observations (e.g., score odor on scale from 1 - 5, with $1=$ very unpleasant odor and $5=$ no discernable odor) and graph the scale values versus treatment step. Create your graph in the space below. 